\title{
A comparative study on monomer elution and cytotoxicity of different adhesive restoration materials
}

\section{Tuğba Toz, Arlin Kiremitçi, Anıl Sera Çakmak, Oya Ünsal Tan, Erhan Palaska, Menemşe Gümüşderelioğlu \& Mutlu Özcan}

To cite this article: Tuğba Toz, Arlin Kiremitçi, Anıl Sera Çakmak, Oya Ünsal Tan, Erhan Palaska, Menemșe Gümüșderelioğlu \& Mutlu Özcan (2017) A comparative study on monomer elution and cytotoxicity of different adhesive restoration materials, Journal of Adhesion Science and Technology, 31:4, 414-429, DOI: 10.1080/01694243.2016.1215768

To link to this article: https://doi.org/10.1080/01694243.2016.1215768

\section{Published online: 01 Aug 2016.}

\section{Submit your article to this journal}

Llll Article views: 198

View related articles 5

View Crossmark data $₫$

Citing articles: 1 View citing articles 


\title{
A comparative study on monomer elution and cytotoxicity of different adhesive restoration materials
}

\author{
Tuğba Toz ${ }^{a}$ Arlin Kiremitçib (iD, Anıl Sera Çakmakc,d (D), Oya Ünsal Tan, Erhan Palaskae, \\ Menemşe Gümüşderelioğlu ${ }^{c, d}$ and Mutlu Özcan ${ }^{f}$
}

\begin{abstract}
aFaculty of Dentistry, Department of Restorative Dentistry, School of Dentistry, Istanbul Medipol University, Istanbul, Turkey; ${ }^{b}$ Faculty of Dentistry, Department of Restorative Dentistry, Hacettepe University, Ankara, Turkey; ' Faculty of Engineering, Department of Chemical Engineering, Hacettepe University, Ankara, Turkey; ${ }^{\mathrm{d}}$ Faculty of Engineering, Department of Bioengineering, Hacettepe University, Ankara, Turkey; ${ }^{\text {eFaculty of }}$ Pharmacology, Department of Pharmaceutical Chemistry, Hacettepe University, Ankara, Turkey; ${ }^{\text {fDental }}$ Materials Unit, Center for Dental and Oral Medicine, Clinic for Fixed and Removable Prosthodontics and Dental Materials Science, University of Zurich, Zurich, Switzerland
\end{abstract}

\begin{abstract}
This study evaluated monomer release and cytotoxicity of different adhesive restoration materials used for dental restorations. The extracts (1,2, and 7 days) of three types of adhesive dental restoration materials, [Quixfill (QF), Silorane Restorative (SR), and Ketac N 100 Restorative (KR)], and the adhesive resins, [XP Bond (XP), Silorane Primer (SP), Ketac N 100 Primer (KP), and Silorane Bond (SB)] were analyzed using high performance liquid chromatography/mass spectrometry (HPLC-MS). The cytotoxicity levels were determined at different time points $(24,48$, and 72 h) of cell culture using 3-(4,5-dimethyl2-thiazolyl)-2,5-diphenyl-2H tetrazolium bromide (MTT) assay. All adhesive resin materials showed monomer release at varying amounts with the highest release after 7 days. The lowest amount of release was observed in QF and the highest with KP. Bis-Phenol A (BPA) was not detected in SP and KR that contain bisphenol-A diglycidyl ether dimethacrylate (bis-GMA). Decamethylpenthasiloxane (D5) was not eluted from SR. Except for SR and QF, all other adhesive restoration materials showed different degrees of toxicity along with different monomer release kinetics. The correlation between the monomer release and cytotoxicity of the materials indicated that the cytotoxicity of the materials increased with the monomer release (Spearman's rho correlation coefficient $-r)$. The correlation after $48 \mathrm{~h}$ was statistically significant $(r=-0.342, p=0.017)$.
\end{abstract}

\section{ARTICLE HISTORY}

Received 12 May 2016

Revised 7 July 2016

Accepted 12 July 2016

\section{KEYWORDS}

Adhesion; cytotoxicity; high-performance liquid chromatography; L929 cell culture; monomer release

\section{Introduction}

Resin-based composite materials and amalgam are both accepted as appropriate materials for the direct restoration of class I and II cavities in restorative dentistry. However, according to the current dental concepts, resin composites are considered as the most suitable direct posterior filling materials since they also allow for minimal invasive restorations.[1] 
The polymerizable matrix of resin materials usually contains one or more base monomers such as bisphenol-A diglycidyl ether dimethacrylate (bis-GMA) and/or urethane dimethacrylate (UDMA), diluent co-monomers such as ethylene glycol dimethacrylate (EGDMA) and/or triethylene glycol dimethacrylate (TEGDMA), and various additives such as photoinitiators (e.g. camphoroquinone), co-initiators (e.g. dimethyl-aminobenzoic-acid-ester), polymerization inhibitors and photostabilizers (e.g. benzophenone).[2] Despite the improvements in adhesive technologies, drawbacks such as polymerization shrinkage within such materials could not be eliminated.[3] In order to overcome the shortcomings of conventional resin-based composites, dental siloranes have been introduced that consist of a new organic matrix.[4] Siloranes present low polymerization shrinkage due to the ring-opening oxirane monomer, increased hydrophobicity, and thereby increased biocompatibility compared to the conventional resin-based composites. [5]

As an alternative to resin composites, glass ionomers are also commonly used for a number of applications such as base or liner materials, as luting cements for indirect restorations, or as temporary or permanent restorative materials for direct restorations. Glass ionomers present several advantages of biocompatibility, low coefficient of thermal expansion, the ability to adhere to the moist tooth structure without necessitating an intermediate agent that decreases the chair-side of the treatment procedure and anticariogenic properties due to fluoride release compared to methacrylate-based resin composites. However, they have some drawbacks such as poor polishability and less favorable mechanical properties, surface wear, or decreased fracture resistance over time.[6] In an attempt to overcome the disadvantages of glass ionomers, different types of glass ionomers have been developed including resin-modified glass ionomers.[7]

The application of adhesive restoration materials in dentistry has been extensively promoted over the last decade.[8] However, concerns in the dentistry over the generation of biodegradation products have also increased and possible effects of byproducts from composite resin matrix degradation on the function of host cells and micro-organisms are being questioned.[9] The release of unpolymerized components from the polymerizable resin matrix as a result of incomplete polymerization of adhesive restoration materials may influence the biocompatibility of the restorations. [2] Consequently, the amount of monomer elution plays an important role in biocompatibility of adhesive restorative materials.

Chromatographic techniques are helpful in the analysis of compounds released from resin-based dental fillings. The components extracted from resin-modified glass ionomers, compomers, and resin composites could be determined using gas chromatography/mass spectrometry (MS).[10] Unfortunately, base-monomer analysis by gas chromatography is almost impossible due to their low volatility and decomposition at higher temperature in the injection port of the gas chromatograph. One of the few available techniques suitable for the analysis of high-molecular-mass compounds is high-performance liquid chromatography (HPLC), mainly coupled with mass spectrophotometry or diode array detection.[11] Several studies have shown the elution of different monomers such as bis-GMA, TEGDMA, and UDMA, from methacrylate-based resin restoration materials [12] but limited information is available on the monomer release from silorane-based restorative materials. [12-15]

By definition, cytotoxicity of an agent is the cascade of molecular events that interferes with macromolecular synthesis, causing unequivocal functional and structural damage in a cell culture. The interactions of the materials and their components with the cells at a molecular level are responsible for tissue reactions such as inflammation, necrosis, 
immunological alterations, genotoxicity, and apoptosis. [16] The in vitro cytotoxicity tests have the advantage of easy detection of the influence of a material on isolated cells growing in culture plates.[17] A number of methods have been developed such as lactate dehydrogenase assay, bromodeoxiuridine assay [18], and fluorescence microscopy [19] in order to investigate the cytotoxicity of dental resin materials. However, 3-(4,5-dimethyl-2-thiazolyl)2,5-diphenyl-2H tetrazolium bromide (MTT) assay is considered to be more useful to estimate cell densities in small culture volumes and has some advantages, such as simplicity, accuracy, reliability, and efficiency.[20]

The objective of this study, therefore, was to measure the amount of monomers released from different types of adhesive restoration materials with different monomer types using HPLC-MS and HPLC-Ultraviolet (UV) and to assess the cytotoxicity of these materials on L929 mouse fibroblast cultures at different time intervals. The null hypotheses tested were that adhesive restoration materials with different chemistry would not show significant difference in monomer elution kinetics and in cytotoxic effect on cell cultures.

\section{Materials and methods}

\section{Specimen preparation}

Disk-shaped specimens from the tested restorative materials including etch-and-rinse adhesive system 'XP' (XP Bond, Dentsply De Trey, Germany), posterior hybrid composite 'QF' (Quixfill, Dentsply De Trey, Germany), silorane composite 'SR' used with its own self-etch adhesive system including primer 'SP' and bond 'SB' (Silorane, 3 M ESPE, St. Paul, USA), and nano-ionomer 'KR' applied with its own primer 'KP' (Ketac N 100, GC, Tokyo Japan) were prepared (Table 1). Materials were placed in polytetrafluoroethylene (Teflon) molds and processed according to the manufacturer's instructions in a laminar flow chamber (Bioair, Siziano, Italy). The etch-and-rinse adhesive system (XP), primer (SP and KP), and adhesive resin (SB) disks were $5 \mathrm{~mm}$ in diameter and $1 \mathrm{~mm}$ in thickness and adhesive restoration materials (QF, SR, and $\mathrm{KR}$ ) were $5 \mathrm{~mm}$ in diameter and $4 \mathrm{~mm}$ in thickness. The adhesive restorative materials were applied in two layers, while the primers and adhesives were applied in one layer and the surfaces of all materials were covered with a transparent strip to prevent the formation of air-inhibited surface layer. The materials were then photopolymerized using light-emitting diode (LED, Elipar Free Light, 3 M ESPE, St. paul, USA; Light output: $1007 \mathrm{~mW} / \mathrm{cm}^{2}$ ) according to the manufacturers' instructions (40 $\mathrm{s}$ for QF, SR and KR; $20 \mathrm{~s}$ for XP, SP, SB, and KP). The power output of the unit was measured with a radiometer (Cure-Rite, Dentsply-Caulk) before the placement of each restoration. In total, 27 specimens of adhesive restoration materials and 54 specimens of primers and adhesives were prepared.

\section{High-performance liquid chromatography}

\section{Preparation of extracts}

All specimens from material groups were divided into three subgroups ( $n=9$ for the adhesive restoration materials; $n=18$ for primers and adhesives) according to the extraction period (1, 2, 7 days). The extraction period was adjusted accordingly for the methyltetrazolium (MTT) test procedure. Immediately after photopolymerization, the specimens in 
Table 1. The brands, types, manufacturers, batch numbers, and chemical compositions of the adhesive restorative materials tested in this study.

\begin{tabular}{|c|c|c|c|c|}
\hline $\begin{array}{l}\text { Adhesive restor- } \\
\text { ative system }\end{array}$ & $\begin{array}{l}\text { Type of the } \\
\text { material }\end{array}$ & Manufacturer & Batch number & Chemical composition \\
\hline $\begin{array}{l}\text { Adhesive restora- } \\
\text { tive system }\end{array}$ & $\begin{array}{l}\text { Type of the } \\
\text { material }\end{array}$ & Manufacturer & Batch number & Chemical composition \\
\hline $\mathrm{XP}$ bond & $\begin{array}{l}\text { Two-step etch } \\
\text { and rinse } \\
\text { adhesive } \\
\text { system }\end{array}$ & $\begin{array}{l}\text { Dentsply, De } \\
\text { Trey, Konstanz } \\
\text { Germany }\end{array}$ & $0,707,000,223$ & $\begin{array}{l}\text { Carboxylic acid-modified dimeth- } \\
\text { acrylate,phosphoric acid-modified } \\
\text { acrylate resin,urethane dimeth- } \\
\text { acrylate, TEGDMA,HEMA, butylated } \\
\text { benzenediol,ethyl-4-dimethylam- } \\
\text { inobenzoate,camphorquinone, } \\
\text { functionalizedamorphous silica, } \\
\text { t-butanol }\end{array}$ \\
\hline Quixfill & $\begin{array}{l}\text { Methacyr- } \\
\text { late-based } \\
\text { hybrid pos- } \\
\text { terior resin } \\
\text { composite }\end{array}$ & & $07,030,000,799$ & $\begin{array}{l}\text { Resin: urethane dimethacrylate } \\
\text { (UDMA);triethyleneglycol di- } \\
\text { methacrylate (TEGDMA); di- and } \\
\text { trimethacrylate resins; carboxylic } \\
\text { acid-modified dimethacrylate resin; } \\
\text { butylated hydroxy tolüene (BHT); UV } \\
\text { stabilizer, camphorquinone; ethyl-4- } \\
\text { dimethylaminobenzoateFillers: sila- } \\
\text { nated strontium aluminumsodium } \\
\text { fluoride phosphate silicate glass }\end{array}$ \\
\hline Silorane primer & Primer & $\begin{array}{l}3 \text { M ESPE,St. Paul, } \\
\text { USA }\end{array}$ & $20,090,220$ & $\begin{array}{l}\text { 2-Hydroxyethyl methacrylate (HEMA) } \\
\text { bisphenol A diglycidyl ether } \\
\text { dimethacrylate (bis-GMA), water, } \\
\text { ethanol, phosphoric acid-meth- } \\
\text { acryloxy-hexylester mixture, } \\
\text { silane treated silica 1,6-Hexanediol } \\
\text { dimethacrylate,copolymer of acrylic } \\
\text { and itaconic acid,(Dimethylamino) } \\
\text { ethyl methacrylate,dl-Camphorqui- } \\
\text { none,phosphine oxide }\end{array}$ \\
\hline Silorane bond & Adhesive resin & & $20,090,220$ & $\begin{array}{l}\text { Substituted dimethacrylate Silane } \\
\text { treated silica, triethylene glycol di- } \\
\text { methacrylate (TEGDMA), phosphoric } \\
\text { acid methacryloxy-hexylesters- } \\
\text { dl-Camphorquinone 1,6-Hexanediol } \\
\text { dimethacrylate }\end{array}$ \\
\hline Silorane & $\begin{array}{l}\text { Silorane } \\
\text { restorative }\end{array}$ & & $20,090,220$ & $\begin{array}{l}\text { 3,4 epoxycyclohexylethylcyclopolyme- } \\
\text { thylsiloxane,bis-3,4-epoxycyclohex- } \\
\text { ylethylphenylmethylsilane, silanized } \\
\text { glass,yittrium floride, camphorqui- } \\
\text { none }\end{array}$ \\
\hline $\begin{array}{l}\text { Ketac N } 100 \\
\text { Primer }\end{array}$ & $\begin{array}{l}\text { Nano-ionomer } \\
\text { primer }\end{array}$ & 3 M ESPE & $20,070,917$ & $\begin{array}{l}\text { Water, HEMA, acrylic/itaconic acid } \\
\text { copolymer, photo-initiators }\end{array}$ \\
\hline Ketac N 100 & $\begin{array}{l}\text { Photopolym- } \\
\text { erizedna- } \\
\text { no-ionomer } \\
\text { restorative }\end{array}$ & & $20,070,917$ & $\begin{array}{l}\text { Paste A: silane-treated glass, si- } \\
\text { lane-treated ZrO2silica, silane-treat- } \\
\text { ed silica, PEGDMA, HEMA, bis-GMA, } \\
\text { TEGDMAPaste B: silane-treated } \\
\text { ceramic, silane-treated silica, water, } \\
\text { HEMA, acrylic/itaconic acidcopol- } \\
\text { ymer }\end{array}$ \\
\hline
\end{tabular}

each subgroup were weighed (Mettler Toledo, Colombus, USA) and, except for SR, specimens in all groups were placed separately into $10 \mathrm{~mL}$ of $70 \%$ methanol/water solution (Sigma-Aldrich, St Louis, MO USA). The extracting medium for the SR groups was pure methanol solution as it is not soluble in methanol/water solution. The specimens were incubated for 1,2 , and 7 days at $37^{\circ} \mathrm{C}$ in dark. After the incubation period, the specimens were removed and the extracts were analyzed using HPLC. 
Table 2. Monomers, abbreviations, chemical formulas, molecular weights, and chemical structures of the investigated adhesive restoration materials in this study.

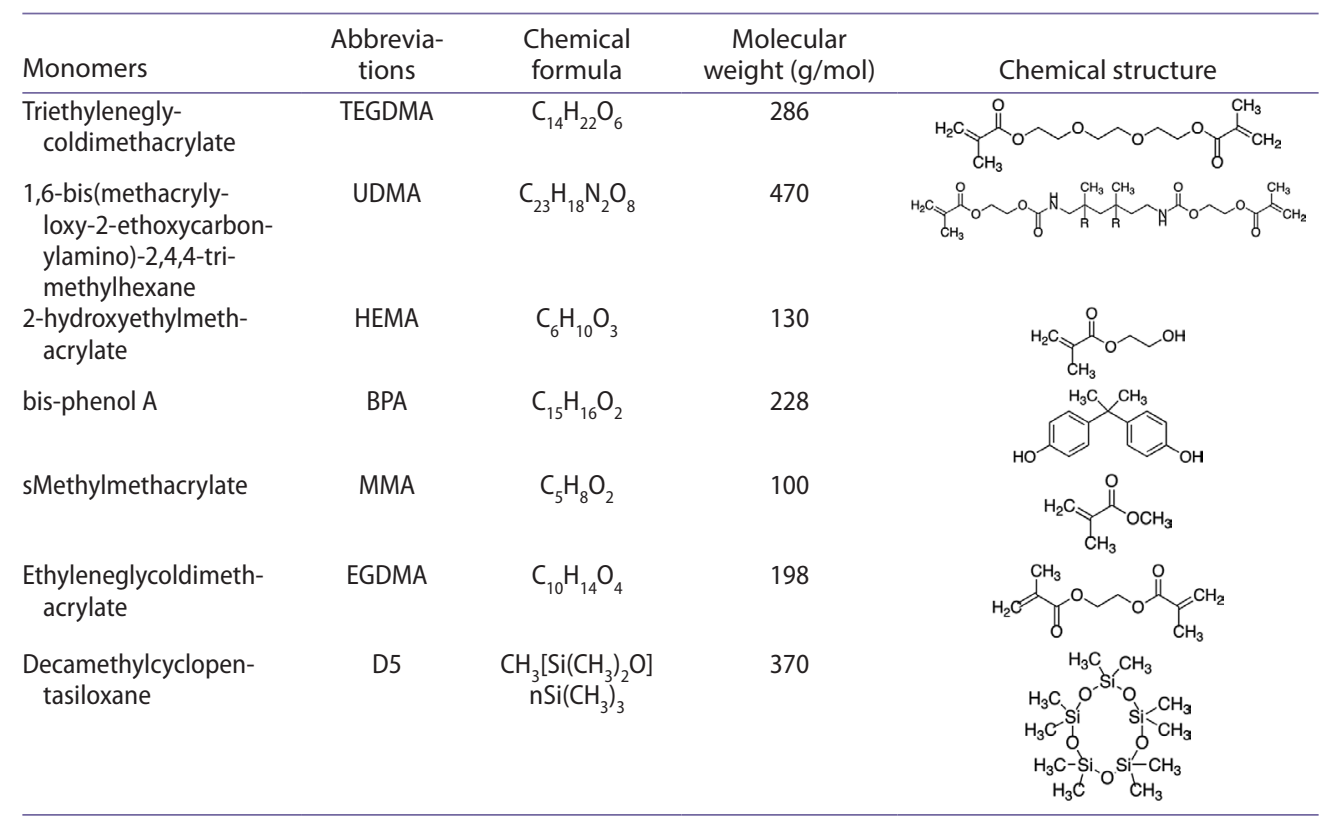

\section{Calibration procedures for HPLC analysis}

The reference monomers [bis-GMA, TEGDMA, UDMA, EGDMA, HEMA (2-hydroxyethyl methacrylate), BPA (bis phenol-A), MMA (methyl methacyrlate), and D5 (decamethylcyclopentasiloxane)] were obtained (Sigma-Aldrich) (Table 2). Stock solutions of reference standards except for D5 (prepared in methanol) were prepared in 70\% methanol/water and stored at $4{ }^{\circ} \mathrm{C}$. The calibration solutions were prepared from these stock solutions by dilution with the same solutions in order to obtain final concentrations of $0.05,0.10,0.20,0.40,0.50$, 0.60 , and $0.80 \mathrm{mg} / \mathrm{mL}$. Triple $20-\mu \mathrm{L}$ injections were made for each standard solution; the peak area for appropriate monomers was determined and plotted vs. concentration using linear regression analysis (Table 3 ).

\section{HPLC analysis}

The analysis of extracts from adhesive materials and reference solutions of the monomers were performed using LC/MS System (Waters Alliance 2695 Separations Module HPLC System, Waters 2996 Photodiode Array Detector and Waters Micromass ZQ Mass Spectrometer, Meadows Instrumentation Inc., Bristol, USA). The stationary phase used was $4 \mathrm{~mm}$ in diameter and $15 \mathrm{~cm}$ in length (C18, Catalog no: 121-1504) column with $5 \mu \mathrm{m}$ particle dimension. The mobile phase was $70 \%$ methanol/water for the extracts, except for SR and methanol was provided for SR extracts $\left(25^{\circ} \mathrm{C}\right)$ at a flow rate of $0.7 \mathrm{~mL} / \mathrm{min}$. A diode array detector was used to analyze the extracts except for SR, and the mass detector was chosen for SR extracts. The detection was performed at a wavelength between 200and $220 \mathrm{~nm}$ for the diode array detector and the analysis of SR extracts was performed with the mass detector (Con voltage: $27.2 \mathrm{~V}$, capillary voltage: $3.84 \mathrm{kV}$, electrospray+, source 
Table 3. Calibration values obtained by linear regression analysis for monomers tested in this study using HPLC-MS.

\begin{tabular}{lccc}
\hline Monomers & Wavelength $(\mathrm{nm})$ & $r^{2}$ & Formula \\
\hline bis-GMA & 201 & 0.989 & $y=\left(3 \times 10^{-8}\right) \times-0.0233$ \\
TEGDMA & 206 & 0.960 & $y=\left(6 \times 10^{-8}\right) \times-0.0798$ \\
UDMA & 206 & 0.996 & $y=\left(6 \times-10^{-8}\right) \times-0.0151$ \\
HEMA & 207 & 0.929 & $y=\left(9 \times 10^{-8}\right) \times-0.1595$ \\
BPA & 202 & 0.968 & $y=\left(5 \times 10^{-8}\right) \times-0.1312$ \\
MMA & 206 & 0.998 & $y=\left(3 \times 10^{-8}\right) \times-0.0047$ \\
EDGMA & 206 & 0.986 & $y=\left(2 \times 10^{-8}\right) \times-0.0038$ \\
\hline
\end{tabular}

temperature: $100{ }^{\circ} \mathrm{C}$, desolation temperature: $120^{\circ} \mathrm{C}$, cone gas flow: $50 \mathrm{~L} / \mathrm{h}$, desolation gas flow: $500 \mathrm{~L} / \mathrm{h}$ ). The injection volume was $20 \mu \mathrm{L}$ and the elution time for the extracts was $15 \mathrm{~min}$ including bis-GMA, whereas for the remainder it was $6 \mathrm{~min}$. The monomers were identified by comparing their elution times with those of the reference monomers under the same conditions in the HPLC. All measurements were performed three times. The average weight of each released monomer, per weight of adhesive materials, except SR was expressed in $\mu \mathrm{g} / \mathrm{mL}$. Quantification of the eluted substances from SR could not be performed because the monomers were not available as individual reference materials. However, calculating and comparing the area of the monomer peaks at different extraction time intervals performed a semi-quantitative comparison of the eluted silorane monomers. The amount of each monomer was proportional to the area of its peak.

\section{Cytotoxicity test}

The cytotoxicity test was conducted according to the ISO 10993/EN 30990 standard using L929 fibroblasts.[21]

\section{Cultivation of L929 fibroblasts}

The murine fibroblast cell line L929 in the third passage was obtained (HUKUK Cell Line Collection, no: 92123004 Foot and Mouth Disease Institute, Ankara, Turkey). The cells were grown as monolayer culture in $25 \mathrm{~cm}^{2}$ flasks in Dubelcco's modified Eagle's medium (DMEM, Sigma Chemical Co.) supplemented with 10\% fetal bovine serum (FBS, Hyclone, Utah, USA) and $1 \%$ penicillin/streptomycin at $37^{\circ} \mathrm{C}$ in an incubator (Heraeus, Germany) containing 5\% $\mathrm{CO}_{2}$ at $95-98 \%$ humidity. The fibroblasts were passaged by trypsinization. Next, they were centrifuged and suspended in 24-well tissue culture plates of 1-mL aliquots, containing $5 \times 104$ cells $/ \mathrm{mL}$.

\section{Preparation of extracts}

All specimens from material groups were divided into three subgroups according to the extraction time intervals (1, 2, 7 days). The disk-shaped specimens of all subgroups were immersed separately in $10 \mathrm{~mL}$ of culture medium (extract solution, DMEM, Sigma) immediately after photopolymerization. The specimens were incubated for 1,2 , and 7 days at $37^{\circ} \mathrm{C}$ in a $\mathrm{CO}_{2}$ incubator ( $n=9$ for the adhesive restorative materials; $n=18$ for primers and adhesives). The ratio of specimen surface area $\left(\mathrm{cm}^{2}\right)$ to the volume of the culture medium $(\mathrm{mL})$ was adjusted to approximately 1 for primers and adhesives and 0.9 for restoration 
materials, which was within the recommended range of $0.5-6.0 \mathrm{~cm}^{2} / \mathrm{mL}$.[14] After the incubation periods, the specimens were removed from the culture medium and the extracts were filtered ( $0.22 \mu \mathrm{m}$ filter, Milipore, Sigma Chemical Co.).

\section{Exposure of cell cultures to test specimens}

The cell suspension was stained with Trypan Blue (Sigma Chemical Co.), counted using a Neubauer chamber and seeded in 24-well plates (Nunc, Sigma-Aldrich, Copenhagen, Denmark) at a density of $1 \times 104$ cells/well. Cultures were incubated for $24 \mathrm{~h}$ at $37^{\circ} \mathrm{C}$ and $5 \%$ $\mathrm{CO}_{2}$. After $24 \mathrm{~h}$, the culture medium was removed from the wells and equal volumes $(1 \mathrm{~mL})$ of the extracts of the tested materials obtained after three time intervals (1,2, 7 days) were added into each well. The original culture medium served as control in the current study.

\section{Evaluation of cell morphology}

Morphologic alteration of L929 cells was observed directly using an optical microscope (Olympus IX71, Tokyo, Japan) and photos were taken using a camera (Olympus C-400).

\section{Mitochondrial activity}

Cell metabolic activity was evaluated through the mitochondrial activity analysis using MTT test that detects the presence of succinic dehydrogenase enzyme (SDH) active in viable cells [22]. The succinic dehydrogenase activity has shown to be a reasonable representative of mitochondrial activity in the cells and reflects both cell number and activity. Cultures were incubated for 24,48 , and $72 \mathrm{~h}$ at $37^{\circ} \mathrm{C}$ and $5 \% \mathrm{CO}_{2}$. The medium was then removed and cell cultures were rinsed with PBS and $600 \mu \mathrm{L}$ per well DMEM without serum and $60 \mu \mathrm{L}$ MTT (tetrazolium salt 3-[4,5-dimethylthiazol-2-yl]-2,5-diphenyltetrazolium bromide) solution $(2.5 \mathrm{mg} / \mathrm{mL}$ in PBS) were added to each well and incubated in a dark environment for $3 \mathrm{~h}$. After the incubation period $\left(37^{\circ} \mathrm{C}, 5 \% \mathrm{CO}_{2}\right), 200 \mu \mathrm{L}$ of supernatant was removed and 400 $\mu \mathrm{L}$ of isopropanol (Merck, Darmstadt, Germany) was added to each well. Subsequently, the absorbance at $570 \mathrm{~nm}$ was measured using spectrophotometer with a microplate reader (Asys UVM 340, Biochrom, Victoria, Australia) with a reference of $690 \mathrm{~nm}$. Measurements were performed three times. The cell viability was calculated according to the Equation (1):

\section{Cell viability (\%)}

$=($ Optical densities of test groups/Optical densities of control groups $) \times 100$

\section{Statistical analysis}

Data were analyzed using a statistical software package (SPSS Software V.20, Chicago, IL, USA). The differences in the release of each component from different adhesive materials were analyzed using one-way analysis of variance (ANOVA) and repeated measures of variance analysis to determine the variability of the monomer elution between three different extraction time intervals. The variability in the toxicity of adhesive materials among the three different extraction intervals and incubation periods was analyzed using repeated measure of variance analysis. Bonferroni post hoc test was used to determine the differences 
Table 4. The mean values and standard deviations of the amounts of monomers $(\mu \mathrm{g} / \mathrm{mL})$ released from each tested material.

\begin{tabular}{|c|c|c|c|c|}
\hline \multirow[b]{2}{*}{ Materials } & \multirow[b]{2}{*}{ Monomers } & \multicolumn{3}{|c|}{ Release of monomers $( \pm S D)(\mu \mathrm{g} / \mathrm{mL})$} \\
\hline & & 1 day & 2 days & 7 days \\
\hline \multirow[t]{3}{*}{ XP Bond } & UDMA & $22.85 \pm 0.06$ & $26.49 \pm 0.11$ & $38.98 \pm 1.07$ \\
\hline & TEGDMA & $0.66 \pm 0.14$ & $2.17 \pm 0.02$ & $10.0 \pm 0.43$ \\
\hline & HEMA & $36.31 \pm 0.15$ & $62.92 \pm 0.22$ & $93.3 \pm 0.56$ \\
\hline \multirow[t]{2}{*}{ Quixfill } & UDMA & $0.38 \pm 0.04$ & $0.02 \pm 0.00$ & $0.43 \pm 0.005$ \\
\hline & TEGDMA & $0.76 \pm 0.02$ & $0.26 \pm 0.04$ & $0.32 \pm 0.02$ \\
\hline \multirow[t]{3}{*}{ Silorane primer } & HEMA & $4.02 \pm 0.60$ & $9.97 \pm 0.93$ & $27.14 \pm 1.31$ \\
\hline & bis-GMA & $11.47 \pm 0.07$ & $16.66 \pm 0.19$ & $14.10 \pm 0.13$ \\
\hline & BPA & Not detected & Not detected & Not detected \\
\hline Silorane bond & TEGDMA & $1.44 \pm 0.04$ & $1.76 \pm 0.00$ & $3.11 \pm 0.05$ \\
\hline Ketac N 100 primer & HEMA & $101.94 \pm 0.96$ & $112.64 \pm 0.45$ & $143.78 \pm 0.16$ \\
\hline \multirow[t]{5}{*}{ Ketac N 100 restorative } & HEMA & $0.08 \pm 0.00$ & $0.78 \pm 0.02$ & $6.35 \pm 0.09$ \\
\hline & bis-GMA & $0.02 \pm 0.00$ & $0.97 \pm 0.00$ & $4.81 \pm 0.08$ \\
\hline & TEGDMA & $0.08 \pm 0.00$ & $3.49 \pm 0.00$ & $6.48 \pm 0.00$ \\
\hline & EGDMA & $0.09 \pm 0.00$ & $0.08 \pm 0.00$ & $0.09 \pm 0.00$ \\
\hline & BPA & Not detected & Not detected & Not detected \\
\hline
\end{tabular}

between the toxicity of the materials. The relationship between the monomer release and toxicity was analyzed using the Spearman's rho correlation test $(-1<r<1)$. $P$ values less than 0.05 were considered to be statistically significant in all tests.

\section{Results}

\section{Monomer release}

All tested materials released monomers at varying amounts at each time interval. The retention times of UDMA, TEGDMA, HEMA, bis-GMA, MMA, BPA, and D5 were in the order of $4.93,3.32,2.17,11.17,2.77,3.18$, and $4.66 \mathrm{~min}$, respectively (Table 4). HEMA release from XP was significantly higher than the two other monomers (TEGDMA and UDMA) $(p<0.001)$. The least amount of monomer release was detected for the hybrid posterior resin composite, QF, containing UDMA and TEGDMA. Different HEMA and bis-GMA release characteristics were observed from SP during different extraction intervals. Although bisGMA release was the highest at the end of the 1st day, HEMA release was the highest at the end of the 7th day. The release of the single monomer (TEGDMA) in SB increased during the extraction interval. Significantly higher amounts of the monomer (HEMA) were released from the nano-ionomer, KP, compared to the other materials $(p<0.001)$. The release of monomers (HEMA, bis-GMA and TEGDMA) increased with the extraction period while TEGDMA monomer of the polyethylene glycol dimethacrylate (PEGDMA) in KR eluted at similar levels at the 1 st, $2^{\text {nd }}$, and 7 th days of extraction. No release of BPA was detected from the two adhesive materials (SP and KR including bis-GMA) tested.

The substances released from SR were identified based on the mass spectra of each peak in the chromatogram. The structure and the molecular weight of different substances were evaluated [13]. According to the chromatogram of the SR extract, a peak of a monomer with a molecular weight of $370 \mathrm{~g} / \mathrm{mol}$ was detected (Figure 1). The retention time of this peak was $3.14 \mathrm{~min}$. Thus, the only monomer released from all extracts of SR was the silorane monomer, bis-3,4-epoxycyclohexylethyl-phenylmethylsilane, with a molecular weight of $370 \mathrm{~g} / \mathrm{mol}$ and the release of this monomer increased with longer extraction intervals. 


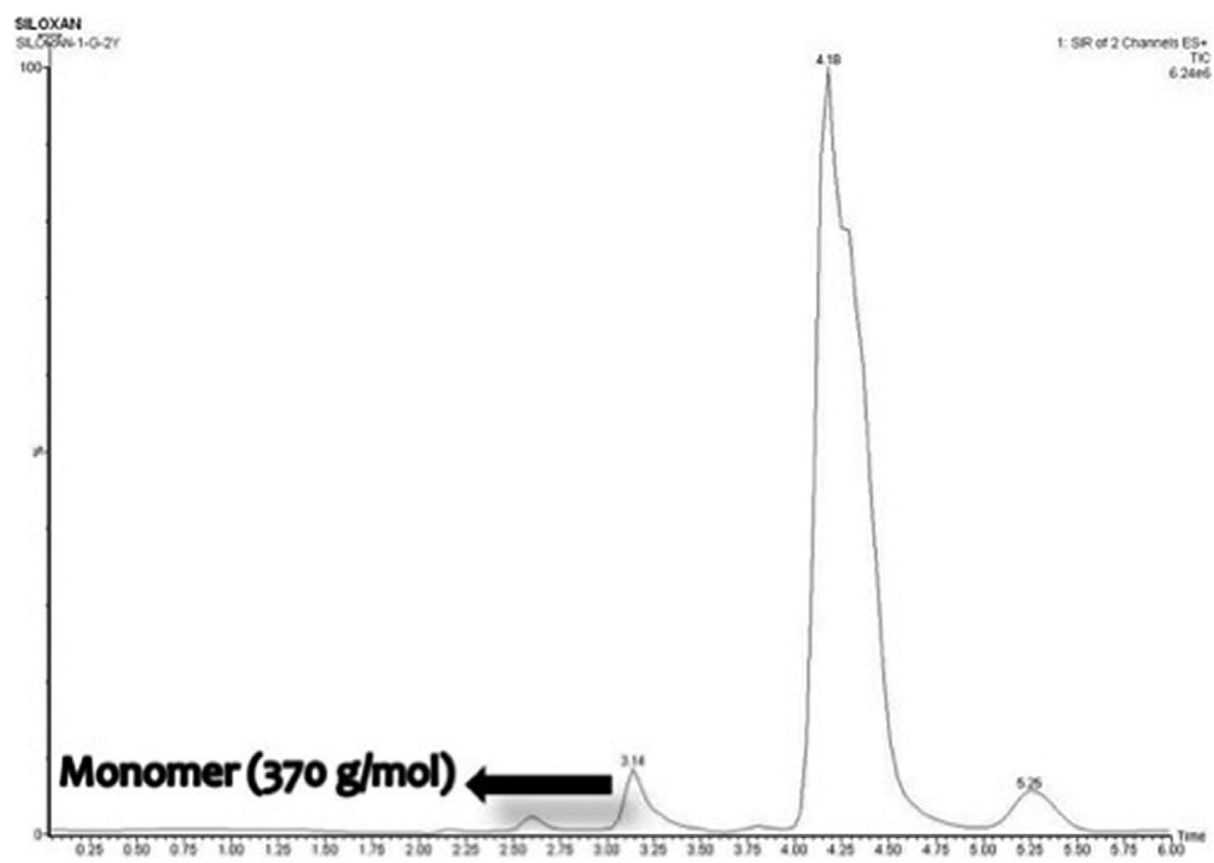

Figure 1. The chromatogram of silorane restorative extract of 2 days.

\section{Cytotoxicity results}

\section{Morphologic assessment}

L929 cells in the culture medium (control) showed typical fibroblastic morphology (Figure 2). The cells incubated with QF extracts for $48 \mathrm{~h}$ showed a spindle-shaped morphology similar to the typical fibroblastic morphology of control cells. The cultures incubated with SR ( 1 and 2 days) extracts for $72 \mathrm{~h}$ were spindle-shaped in appearance similar to the control cells. The cells incubated with KP extracts for $24 \mathrm{~h}$ were round in shape and additionally led to the enlargement of the intercellular space. The cells treated with SP for $48 \mathrm{~h}$ and KR extracts for $72 \mathrm{~h}$ had morphologies similar to that of the cells incubated with $\mathrm{KP}$ extracts for $24 \mathrm{~h}$ (Figure 2).

\section{Cell viability}

After 24h incubation, 1-, 2-, and 7-day extracts of QF, SR, and SB were found to be nontoxic to the L929 cell cultures (Figure 3). When 1-day extracts were taken into account, the most toxic material was KP. The differences among the toxicities of 1-, 2-, 7-day extracts of QF, XP, $\mathrm{SP}, \mathrm{SB}, \mathrm{KR}$, and KP were not statistically significant $(p>0.05)$. The cell survival rate of the 1 -day extracts of SR was significantly higher than that of the seven-day extracts $(p=0.006)$ (Figure 3). After $48 \mathrm{~h}, 1$ - and 2-days extracts of SR and all extracts of QF were biocompatible with the cells. After $72 \mathrm{~h}, 1$ - and 2-days extracts of SR were biocompatible to the cells and similar to the results of $48 \mathrm{~h}$ (Figure 3). When the toxicities of the 1-day extracts of all tested materials after different incubation periods were compared, differences among the cell survival rates of KP, KR, SP, and XP were found to be statistically not significant $(p>0.05)$. 


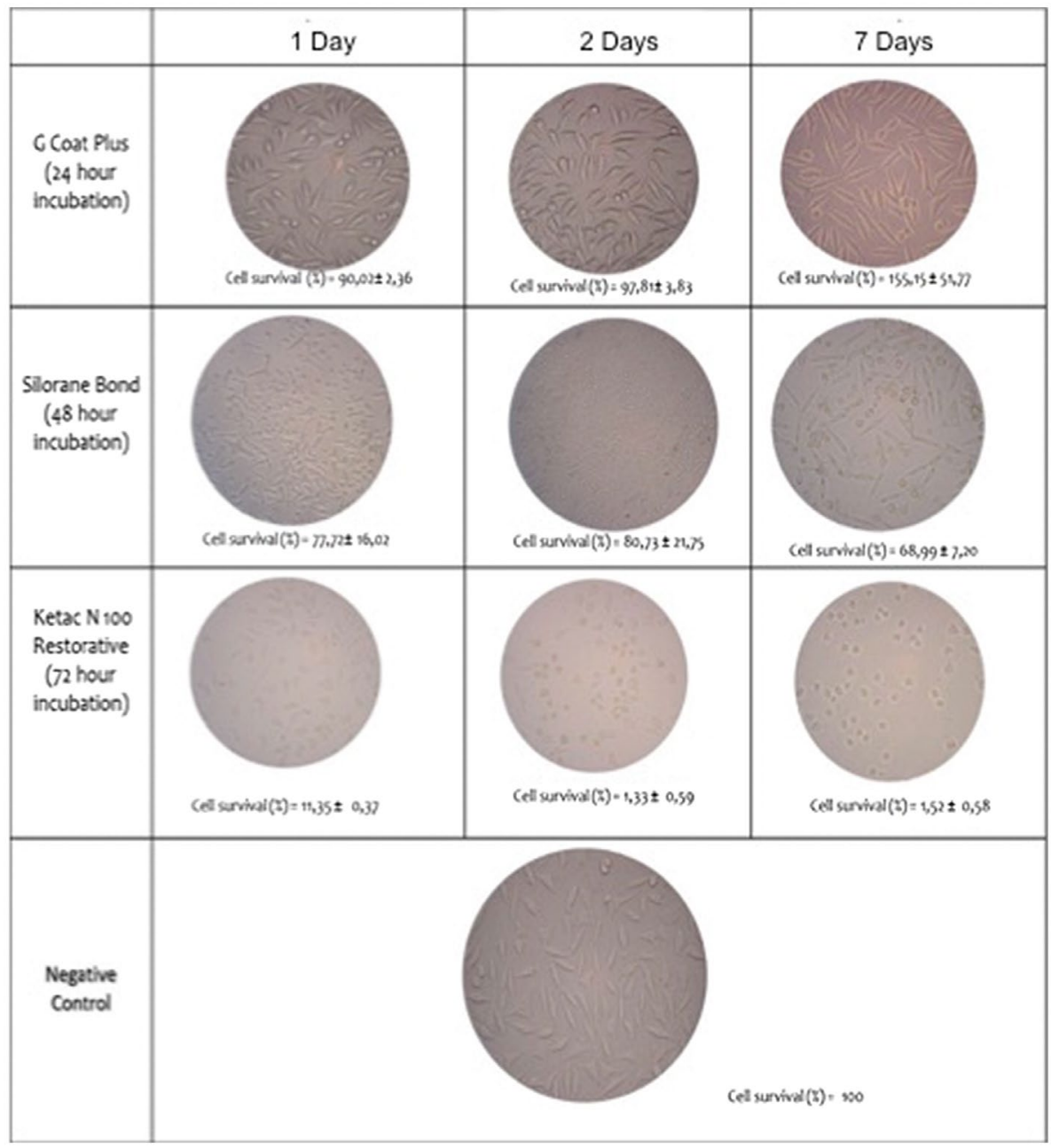

Figure 2. Morphological views of L929 fibroblasts interacted with 1, 2 and 7-day extracts of Silorane Bond and Ketac N 100 Restorative after 24, 48, and 72 h of incubation intervals, respectively.

When the toxicities of 2-and 7-days extracts were compared after different incubation intervals, the differences among the materials were not statistically significant $(p>0.05)$.

The correlation between the monomer release and cytotoxicity of the materials indicated that the cytotoxicity of the materials increased with the monomer release (Spearman's rho correlation coefficient $-r)$. The correlation after $48 \mathrm{~h}$ was statistically significant $(r=-0.342, p=0.017)$.

\section{Discussion}

This study was undertaken to measure the amount of monomers released from different types of adhesive restoration materials with different monomer types and to assess the cytotoxicity of these materials on L929 mouse fibroblast cultures at different time intervals. Since the material type with different chemistries showed significant affect on the monomer elution and cytotoxicity on cell cultures, the null hypothesis tested could be rejected. 

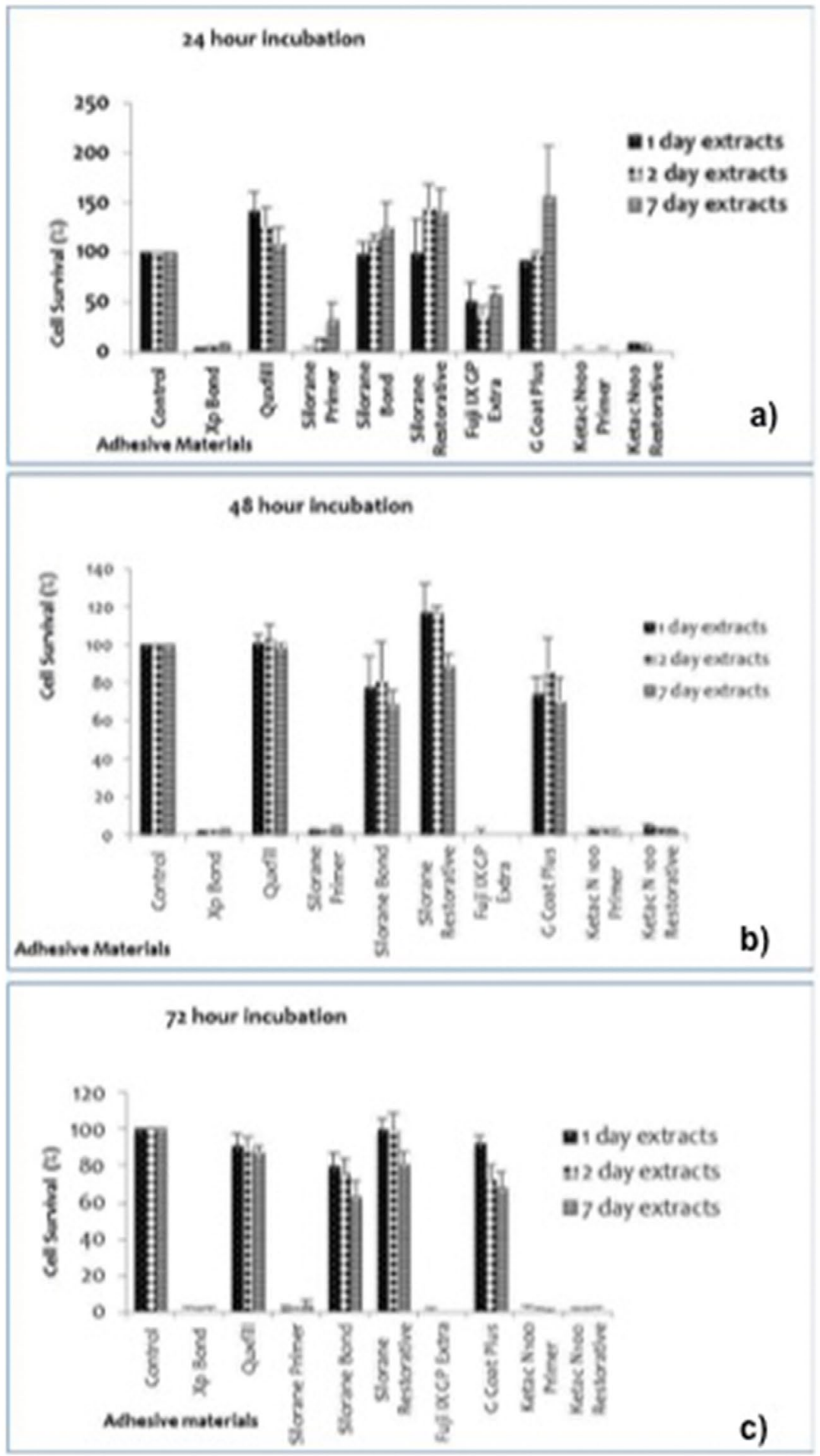

Figures 3(a)-(c). Cell survival percentages of 1-, 2-, and 7-day extracts of adhesive restoration materials tested in this study as a function of incubation period of (a) 24 , (b) 48 , and (c) $72 \mathrm{~h}$. 
In the present study, LC/MS analytical method was used that combines the advantages of an LC instrument with those of a mass spectrometer.[2] Different kinds of solvents, such as distilled water, saliva, ethanol, methanol, and acetonitrile have been used to analyze the monomer release.[23] In this study, 70\% methanol/water was used as an extraction solution. In an in vitro evaluation, it was revealed that almost every compound could be detected in the extracts from methanol, whereas only a few were found in water extracts. [24] Thus, the extracting medium for the SR group was pure methanol due to the solubility of the monomer. To date, there is no published investigation evaluating the monomer release of XP Bond, where HEMA release was significantly higher than the two other monomers (TEGDMA and UDMA). This high amount release from the smallest monomer HEMA (130 g/ mol) is in accordance with a previous study.[25] Smaller molecules have an enhanced mobility and could be eluted at a faster rate than larger bulkier molecules. On the other hand, UDMA does not signify a unique molecule due to different molecular weight and different structure.[26] Although HPLC is usually used to detect the eluted monomers, it does not appear to be adequate in determining different forms of UDMA. For this reason, the combination of HPLC with MS was suitable specifically to identify the eluted compounds of this monomer. XP and QF include different types of UDMA with different molecular structures. Therefore, a mass detector rather than a diode array detector (UV detector) was used. The least amount of monomer release was detected for the hybrid posterior resin composite, QF. It could be explained on the grounds that QF is polymerized quicker due to its high translucency. Similarly, low cytotoxicity of QF is due to its higher conversion rate.[26]

A previous study was chosen as a reference to assess the release of monomers from SR.[13] The core structure of the cyclic silorane monomers resembles to that of the chemical structure of D5 that could be present in the SR as a contaminant or a degradation product. D5 belongs to a group of chemicals known as cyclic volatile methylsiloxanes (CVMS), mainly used in the production of silicone polymers. However, D5 is additionally used directly in personal care products, such as antiperspirants, hair care, and skin care products. $[27,28]$ Recently, concerns have been raised regarding their environmental profile as they have relatively high bioconcentration factors, implying some potential for bioaccumulation.[29] The monomers were identified based on the mass spectra of each peak in the chromatogram. The silorane monomers analyzed according to the reference study [13] showed molecular weights of 370,736 , and $920 \mathrm{~g} / \mathrm{mol}$ and D5 with the molecular weight of $370 \mathrm{~g} / \mathrm{mol}$ that was equivalent to that of the first monomer. However, only one monomer (with a molecular weight of $370 \mathrm{~g} / \mathrm{mol}$ ) was detected. The retention time of the detected monomer was $3.14 \mathrm{~min}$. Since the retention time of the peak observed in the calibration solution of D5 was $4.66 \mathrm{~min}$, it was decided that the peak detected in our study did not belong to D5.[13]

The only monomer HEMA from KP was detected as the most released substance from all tested materials. BPA is present as a trace impurity in the starting materials for resins, and it is additionally a controversial endocrine disruptor.[24] The deleterious effect of BPA on humans with its estrogen-like properties, as a degradation product of bis-GMA-based restoratives are ambiguous. In some studies, BPA was detected [30], whereas in others is not [31]. In the present study, the two materials containing bis-GMA were SP and KR. In the chromatograms of SP, a peak was detected in a similar retention time $(3.18 \mathrm{~min})$ of BPA. However, as previously noted this monomer might not be BPA.[32] Detailed analysis of 
commercial bis-GMA indicated that in addition to bis-GMA and its structural isomer, isobis-GMA， 2,2[4-(2-hydroxy-3-metacryloiroxy-1-propoxy)-4-(2,3-dihydroxy-1-propoxy)] diphenyl-propane (bis-GMA-H) possesses a structure in which one methacrylate ester bond of bis-GMA is hydrolyzed.[32] Thus, bis-GMA-H may appear as a peak overlapping the BPA peak under certain analytical HPLC conditions. Hence, the high BPA content reported in the literature may be due to inappropriate separation conditions. In the present study, the analysis of KR extracts showed a peak with a retention time that was similar to that of the BPA (3.18 min) and TEGDMA (3.32 min). When wavelength of the monomers that showed maximum absorption was considered, wavelength of the peak of KR was 206, equivalent to the wavelength of TEGDMA when it showed maximum absorption. As a result, no BPA release was observed for KR.

The use of permanent cell lines, such as transformed mouse fibroblast (L929) provides good reproducibility for in vitro cytotoxicity screening.[33] In this study, the cytotoxic effect of adhesive materials on L929 cells was investigated using MTT assay where the reduction of MTT by viable cells is a good indicator of toxicity.[22] According to the data obtained from the MTT test, except SR and QF, all restorative materials showed different degrees of toxicity. All extracts of XP were found to be cytotoxic to the cell culture at three time intervals $(24,48$, and $72 \mathrm{~h}$ ) being in agreement with a previous study with the same incubation time.[34]

It has to be noted that the amount of adhesive systems used to prepare the specimens in the present experiment was higher than the amount used in clinical practice. During the restorative procedures, adhesives are applied in layers, and the polymerization of resin composites possibly provides additional polymerization of the adhesive system. Accordingly, when the level of cytotoxicity of the material does not exceed that of the defense capacity of the organism, it can be considered as acceptable. However, the toxicity of leachable components released from adhesive systems should be considered for clinical applications. In this regard, QF was reported as a material that has lower toxicity to cell cultures. [27,35] The low toxicity of QF was explained with the high filler load ( $87 \mathrm{w} \%)$ that would have reduced the amount of resin available for dissolution or the released monomers is of low toxicity by nature.[35] The high polymerization due to its high translucency possibly yielded higher conversion rate of the material.[27] Furthermore, the combined reaction of the two monomers (UDMA and TEGDMA) of QF, in the disturbance of the cell cycle was found to be less as compared to that of each compound individually. [36] On the contrary, SP including HEMA and bis-GMA as monomers was found to be toxic to the cell culture. This could be due to hydrophilicity and low molecular weight of HEMA and high toxicity of bis-GMA. [37] Low concentrations of bis-GMA could antagonize the cytotoxicity of HEMA but higher concentration of bis-GMA is likely to cause synergism regardless of the concentration of HEMA.[38] However, it increased the toxicity in combination with HEMA.

SB was toxic after the incubation period of 48 and $72 \mathrm{~h}$, whereas it was less toxic after $24 \mathrm{~h}$ incubation. This adhesive material includes TEGDMA that has lower toxicity than those of bis-GMA and UDMA. However, it has been showed that released TEGDMA was generally higher compared to other monomers. [39] On the other hand, silorane-based restorative composites have shown comparable [40] or better [41] cytotoxic characteristics to clinically successful dimethacrylate composites. In the present study, SR was biocompatible except for the 7 -day extracts after $72 \mathrm{~h}$ incubation. The toxicity of this material could be related to the other ingredients, such as camphoroquinone reported as a toxic material.[42] 
In the present study, KP and KR also showed toxicity. The toxicity of KP could be explained with the monomer ingredient (HEMA) but the toxicity of KR could be related to the monomers (HEMA, PEGDMA, TEGDMA, and bis-GMA), ion release and solubility of the material. High toxicity of resin-modified glass ionomer compared to that of conventional glass ionomers was attributed to the presence of HEMA.[43]

The cytotoxicity of the materials increased with the monomer release where the correlation was significant after $48 \mathrm{~h}$. It has to be however noted that the materials released from these extracts were not only monomers and may have included barium, aluminum, zinc, and silicon.[44] Moreover, the toxicity of the adhesive materials could in part be related to the initiators. [45] Except from the effects of the different chemical compositions on the biocompatibility of the materials, the antagonistic and synergistic effects of the monomers should also be considered crucial in interpreting toxicity results. [38]

\section{Conclusion}

From this study, the following could be concluded:

(1) All tested adhesive restorative materials showed monomer release kinetics at varying degrees at the time intervals tested.

(2) The least amount of monomer release was detected for the hybrid posterior resin composite, QF, containing UDMA, and TEGDMA.

(3) Except siloxane-based resin composite, SR, and methacrylate-based resin composite, QF, all materials showed different degrees of toxicity.

(4) The most toxic material was KP after 1 day but the differences among the toxicities after 2 and 7 days were not statistically significant between materials tested.

(5) After $48 \mathrm{~h}, 1$ - and 2-days extracts of SR and all extracts of QF were biocompatible with the cells.

(6) The amount of monomer release and cytotoxicity of the materials indicated weak but significant correlation especially after $48 \mathrm{~h}$.

\section{Clinical relevance}

Since the least amount of monomer release was detected for the hybrid posterior resin composite, Quixfill (QF), containing UDMA and TEGDMA, and siloxane-based resin composite (SR) and methacrylate-based resin composite, QF showed the least toxicity, clinicians could consider these adhesive materials as more biocompatible for adhesive restorations.

\section{Disclosure statement}

The authors did not have any commercial interest in any of the materials used in this study.

\section{ORCID}

Arlin Kiremitçi (iD) http://orcid.org/0000-0003-0901-8365

Anıl Sera Çakmak (D) http://orcid.org/0000-0002-5730-2750 


\section{References}

[1] Demarco FF, Correa MB, Cenci MS, et al. Longevity of posterior composite restorations: not only a matter of materials. Dent. Mater. 2012;28:87-101.

[2] Polydorou O, Trittler R, Hellwig E, et al. Elution of monomers from two conventional dental composite materials. Dent. Mater. 2007;23:1535-1541.

[3] Arrais CA, Oliveira MT, Mettenburg D, et al. Silorane- and high filled-based "low-shrinkage" resin composites: shrinkage, flexural strength and modulus. Braz. Oral Res. 2013;27:97-102.

[4] Luhrs AK, Gormann B, Jacker-Guhr S, et al. Repairability of dental siloranes in vitro. Dent. Mater. 2011;27:144-149.

[5] Ilie N, Hickel R. Macro-, micro- and nano-mechanical investigations on silorane and methacrylate-based composites. Dent. Mater. 2009;25:810-819.

[6] Zoergiebel J, Ilie N. Evaluation of a conventional glass ionomer cement with new zinc formulation: effect of coating, aging and storage agents. Clin. Oral Invest. 2013;17:619-626.

[7] Burke FJ, Lucarotti PS. Re-intervention in glass ionomer restorations: what comes next? J. Dent. 2009;37:39-43.

[8] Mjor IA, Moorhead JE, Dahl JE. Selection of restorative materials in permanent teeth in general dental practice. Acta Odontol. Scand. 1999;57:257-262.

[9] Al-Hiyasat AS, Darmani H, Milhem MM. Cytotoxicity evaluation of dental resin composites and their flowable derivatives. Clin. Oral Invest. 2005;9:21-25.

[10] Geurtsen W, Spahl W, Leyhausen G. Variability of cytotoxicity and leaching of substances from four light-curing pit and fissure sealants. J. Biomed. Mater. Res. 1999;44:73-77.

[11] Pulgar R, Olea-Serrano MF, Novillo-Fertrell A, et al. Determination of bisphenol A and related aromatic compounds released from Bis-GMA-based composites and sealants by high performance liquid chromatography. Environ. Health Perspect. 2000;108:21-27.

[12] Miletic V, Santini A, Trkulja I. Quantification of monomer elution and carbon-carbon double bonds in dental adhesive systems using HPLC and micro-Raman spectroscopy. J. Dent. 2009;37:177-184.

[13] Kopperud HM, Schmidt M, Kleven IS. Elution of substances from a silorane-based dental composite. Eur. J. Oral Sci. 2010;118:100-102.

[14] Schulz SD, Konig A, Steinberg T, et al. Human gingival keratinocyte response to substances eluted from Silorane composite material reveal impact on cell behavior reflected by RNA levels and induction of apoptosis. Dent. Mater. 2012;28:e135-142.

[15] Tsitrou E, Kelogrigoris S, Koulaouzidou E, et al. Effect of extraction media and storage time on the elution of monomers from four contemporary resin composite materials. Toxicol. Int. 2014;21:89-95.

[16] Porto IC, Andrade AK, Guenes GM, et al. In vitro potential cytotoxicity of an adhesive system to alveolar macrophages. Braz. Dent. J. 2009;20:195-200.

[17] Kong N, Jiang T, Zhou Z, et al. Cytotoxicity of polymerized resin cements on human dental pulp cells in vitro. Dent. Mater. 2009;25:1371-1375.

[18] Reichl FX, Simon S, Esters M, et al. Cytotoxicity of dental composite (co)monomers and the amalgam component $\mathrm{Hg}(2+)$ in human gingival fibroblasts. Arch. Toxicol. 2006;80:465-472.

[19] Reichl FX, Esters M, Simon S, et al. Cell death effects of resin-based dental material compounds and mercurials in human gingival fibroblasts. Arch. Toxicol. 2006;80:370-377.

[20] Malkoc S, Corekci B, Ulker HE, et al. Cytotoxic effects of orthodontic composites. Angle Orthod. 2010;80:571-576.

[21] Sigusch BW, Pflaum T, Volpel A, et al. The influence of various light curing units on the cytotoxicity of dental adhesives. Dent. Mater. 2009;25:1446-1452.

[22] Mosmann T. Rapid colorimetric assay for cellular growth and survival: application to proliferation and cytotoxicity assays. J. Immunol. Method 1983;16:55-63.

[23] Komurcuoglu E, Olmez S, Vural N. Evaluation of residual monomer elimination methods in three different fissure sealants in vitro. J. Oral Rehabil. 2005;32:116-121.

[24] Kwon HJ, Oh YJ, Jang JH, et al. The effect of polymerization conditions on the amounts of unreacted monomer and bisphenol A in dental composite resins. Dent. Mater. J. 2015;34:327335. 
[25] Ferracane JL. Elution of leachable components from composites. J. Oral Rehabil. 1994;21:441452.

[26] Polydorou O, Konig A, Hellwig E, et al. Urethane dimethacrylate: a molecule that may cause confusion in dental research. J. Biomed. Mater. Res. B. Appl. Biomater. 2009;91:1-4.

[27] Franz A, Konradsson K, Konig F, et al. Cytotoxicity of a calcium aluminate cement in comparison with other dental cements and resin-based materials. Acta. Odontol. Scand. 2006;64:1-8.

[28] Sparham C, Van Egmond R, O'Connor S, et al. Determination of decamethylcyclopentasiloxane in river water and final effluent by headspace gas chromatography/mass spectrometry. J. Chromatogr. A. 2008;28:124-129.

[29] Whelan MJ, Van Egmond R, Gore D, et al. Dynamic multi-phase partitioning of decamethylcyclopentasiloxane (D5) in river water. Water Res. 2010;44:3679-3686.

[30] Polydorou O, Konig A, Hellwig E, et al. Long-term release of monomers from modern dentalcomposite materials. Eur. J. Oral Sci. 2009;117:68-75.

[31] Ortengren U, Wellendorf $\mathrm{H}$, Karlsson S, et al. Water sorption and solubility of dental composites and identification of monomers released in an aqueous environment. J. Oral Rehabil. 2001;28:1106-1115.

[32] Ohsaki A, Imai Y. Analysis of major components contained in Bis-GMA monomer. Dent. Mater. J. 1999;18:425-429.

[33] Schmid-Schwap M, Franz A, Konig F, et al. Cytotoxicity of four categories of dental cements. Dent. Mater. 2009;25:360-368.

[34] Trubiani O, Caputi S, Di Iorio D, et al. The cytotoxic effects of resin-based sealers on dental pulp stem cells. Int. Endod. J 2010;43:646-653.

[35] Koulaouzidou EA, Papazisis KT, Yiannaki E, et al. Effects of dentin bonding agents on the cell cycle of fibroblasts. J. Endod. 2009;35:275-279.

[36] Wisniewska-Jarosinska M, Poplawski T, Chojnacki CJ, et al. Independent and combined cytotoxicity and genotoxicity of triethylene glycol dimethacrylate and urethane dimethacrylate. Mol. Biol. Rep. 2011;38:4603-4611.

[37] Kaga M, Noda M, Ferracane JL, et al. The in vitro cytotoxicity of eluates from dentin bonding resins and their effect on tyrosine phosphorylation of L929 cells. Dent. Mater. 2001;17:333-339.

[38] Ratanasathien S, Wataha JC, Hanks CT, et al. Cytotoxic interactive effects of dentin bonding components on mouse fibroblasts. J. Dent. Res. 1995;74:1602-1606.

[39] Lee DH, Lim BS, Lee YK, et al. Involvement of oxidative stress in mutagenicity and apoptosis caused by dental resin monomers in cell cultures. Dent. Mater. 2006;22:1086-1092.

[40] Madhyastha PS, Naik DG, Kotian R, et al. Evaluation of cytotoxicity of silorane and methacrylate based dental composites using human gingival fibroblasts. J. Clin. Diagnost. Res. 2015;9:ZC05-8.

[41] Shafiei F, Tavangar MS, Razmkhah M, et al. Cytotoxic effect of silorane and methacrylate based composites on the human dental pulp stem cells and fibroblasts. Med. Oral Patol. Oral y Cir. Bucal. 2014;19:e350-8.

[42] Li YC, Huang FM, Lee SS, et al. Protective effects of antioxidants on micronuclei induced by camphorquinone/ $\mathrm{N}, \mathrm{N}$-dimethyl-p-toluidine employing in vitro mammalian test system. J. Biomed. Mater. Res. B. Appl. Biomater. 2007;82:23-28.

[43] Nicholson JW, Czarnecka B. The biocompatibility of resin-modified glass-ionomer cements for dentistry. Dent. Mater. 2008;24:1702-1708.

[44] Oysaed H, Ruyter IE. Water sorption and filler characteristics of composites for use in posterior teeth. J. Dent. Res. 1986;65:1315-1318.

[45] Floyd CJ, Dickens SH. Network structure of Bis-GMA- and UDMA-based resin systems. Dent. Mater. 2006;22:1143-1149. 